\title{
Changing infection control behaviour in Egypt
}

\author{
Hala Badawi and Manal El Said \\ Theodor Bilharz Research Institute (TBRI), Warrak, Egypt \\ doi:10.3396/ijic.V4s1.021.08
}

\begin{abstract}
The infection control unit at the Theodor Bilharz Research Institute in Egypt describes how it responded to the challenge of changing a culture of infection control practice in the workplace. Improved disposal of healthcare waste, the introduction of hand hygiene facilities and the design of a central sterilisation unit are some of the measures being introduced to raise awareness of infection control in the institute. The team also found that mupirocin nasal applications on healthcare workers with Methicillin Resistant Staphylococcus aureus (MRSA) colonisation resulted in nasal carriage clearance.
\end{abstract}

\section{Introduction}

Theodor Bilharz Research Institute (TBRI) is a government medical research institution in Egypt. The laboratories and hospital opened in 1978 and 1983, respectively, following a deal between the governments of the Federal Republic of Germany and Egypt.

One of the important challenges for the hospital was finding healthcare personnel interested in the field of infection control. Two infection control teams were created: one team to represent the different hospital departments and the other to represent laboratory departments. Monthly meetings were held between them, but no financial support was given. Upon evaluating the performance of the teams, it was found that only a few members of both teams were attending these meetings.
The selection process for an infection control team changed, after achieving financial assistance. Only active members that made a real change in their departments were considered. It was decided to modify the training policy by making a schedule for weekly visits to each department or unit for training, guidance and follow up.

By creating a team of healthcare personnel with an interest in infection control, infection control policies can now be applied in the different departments. Financial support has also had an encouraging effect and the weekly visits have proved to be more practical, with much better feedback.

Now the infection control unit at the hospital includes four infection control doctors and four infection control nurses.

\section{Corresponding author}

Prof Dr Hala Badawi, Theodor Bilharz Research Institute (TBRI), Warrak, Egypt

Email: halabadawi2@yahoo.com and manalmicrobiology@yahoo.com 


\section{Methods}

The team has had to face many hurdles to change infection control practice within the institute and to create a safer environment for patients. These include:

\section{Waste disposal}

There was no system available for waste disposal at the institute. Healthcare workers would remove all the waste in one type of bag, including sharp waste. The open bags were collected through the hospital and then transferred outside the institute in public waste containers.

\section{Hand hygiene}

The team designed an audit to evaluate the degree of compliance with hand washing by health workers and the availability of cleaning facilities. There were inadequate and inconveniently located hand hygiene facilities. Hand washing sinks were with hand taps. No elbow, wrist, sensor, mixer, foot-operated taps were available, except in the operation theatre. There were no soap pump dispensers, wall-mounted paper towels or foot operated waste bins with lids at each hand washing area.

\section{Laundry equipment}

There was a shortage of washing machines and dryers at the institute. The clothes and linen had to be hung near the ground with the risk of being soiled. Also, there was no separation between the entrance of soiled linen and the exit of clean linen because the original entrance became occupied with some engineering activities.

\section{Pest control}

No one can deny the side effects of different chemicals used for washing textiles or pest control. These methods are also costly to the hospital. For example, pests control costs about $£ E$ 20,000 (approximately $£ 1,900$ ) per year. The presence of an old incinerator emitting a large amount of toxic gases was also a big problem.

\section{MRSA}

The team faced the challenge of assessing the epidemiological emergence of MRSA clinical isolates in the hospital, so as to evaluate the antibiotic policy and infection control program.

\section{Sterilisation}

One of the important problems faced was the absence of a central sterilisation unit, as it was occupied partly by the engineering department and partly by the storage department. The central steriliser was situated in the middle. The surgical instruments and wraps were sterilised in the operating department.

\section{Communication}

The institute started the distribution of an Arabic version of its infection control guideline booklet. Evaluation of the effectiveness of this booklet on the application of infection control policies, indicated that the book was not a practical way to attract the attention of the healthcare worker and inform them about infection control. The booklets were often left in cupboards and shelves without any attention. The team changed the methods of policy display, by putting up posters in different departments. But some of these posters were lost or damaged.

\section{Results}

\section{Segregation of waste}

The team studied the problem of waste disposal. They revised Centre for Disease Control and Prevention (CDC) and World Health Organisation (WHO) rules; collected information about all possible resources; and discussed possible solutions with the hospital manager. Now, after a lot of hard work, the institute has:

- A red bag for the collection of infectious waste and a black one for general waste

- Puncture-proof high-density plastic containers fitted with covers for collection of sharps. They are distributed all over the hospital

- Wheeled trolleys for transportation of healthcare waste

Health care workers involved with the collection of waste from different hospital departments were also trained and supplied with personal protective clothes.

A room designed originally for collection and storage of healthcare waste was occupied by painting staff. Great efforts were done to refurbish it; to close its windows with glass; and to appoint a supervisor specifically for the room. A deal has also been reached with a government company to remove the waste periodically from the room using covered cars. 
The team also organised several seminars and lectures for healthcare workers to explain the importance of segregation of waste according to its nature; the importance of tightly closed bags; and the importance of personal protective clothes.

The changes greatly improve the services of safe disposal of healthcare waste in the institute. These procedures help in proper recycling of waste, decrease reported cases of sharp injuries between healthcare workers and provides a safe environment.

\section{Hand washing facilities}

The team studied the problem; revised the CDC and WHO rules; collected information about all possible resources; and discussed the possible solutions with the hospital manager. The institute has now been given approval to supply hospital wards with hand washing facilities - but in steps. The first area with these facilities is the haemodialysis unit and the team will continue to extend them to the whole hospital.

The team has organised several seminars and lectures for health care workers to explain the importance of hand washing. Posters depicting good hand washing technique are being distributed to all clinical departments and hung over clinical hand basins. The team has also started introducing alcohol hand rubs as recommended by the CDC to improve the compliance of health care workers.

These efforts greatly increased the awareness and importance of hand washing and improved compliance of healthcare workers.

\section{Purchase of washing machines and dryers}

The team discussed possible solutions with the hospital manager. After a lot of pressure, the institute has finally been supplied with sufficient numbers of washing machines and dryers at its laundry unit. Engineering activities were transferred to another place in the hospital, leaving the entrance for the laundry open so that the institute has two doors, one for the entrance of soiled linen and the other for the exit of clean linen.

The new machines have greatly improved the quality of cleaning and drying in the laundry. They have also resulted in a considerable decrease of workload.

\section{Introduction of surveillance programmes}

The institute has participated in surveillance programmes organised by the European Commission and Nosocomial Infection Control Center (NICC) of General Organization for Teaching Hospital and Institutes (GOTHI), Egypt, for "Strengthening Health Care Epidemiology of Nosocomial Infection in the Mediterranean Area" (NOSOMED). These surveys include:

- A prevalence survey of nosocomial infection in 2003.

- An incidence survey of surgical site infection, for three months from August 2003 to November 2003.

- Auditing of quality in sterilisation in 2004.

- Antibiotic resistance surveillance from the microbiology laboratory from January 2005 to June 2005.

This helped the team detect shortcomings in hospital practice. One such problem was the need for a system for notification of nosocomial infections in the hospital wards. Accordingly, the team designed a simple sheet to be filled by the doctor or the nurse in the wards and to be sent to the infection control unit to be completed by the team. Also, they arranged for stronger links with the clinical laboratories, particularly the microbiology laboratory, to inform the unit as promptly as possible about any nosocomial infections. Also, the team wrote the instructions for isolation precautions, to be distributed with notified cases so as to take suitable actions within a suitable time.

These procedures were very effective in decreasing the infection rates and improving the recording system at the hospital. They also provided the hospital with statistical data which can be compared, helping the team perform epidemiological investigations if any outbreak occurred.

\section{Isolating MRSA}

The team proceeded to isolate MRSA clinical isolates from patients and health care. Isolates collected from hospitalised patients in TBRI during a period of four months, from September to December 2001 (after the construction of an infection control unit) and 
corresponding periods in 2004, were screened for the presence of MRSA. Nasal swabs were collected from health care workers (HCWs) during the same periods.

The overall nosocomial infection rates were $12.6 \%$ and $5.8 \%$ in the first and second periods respectively. The overall MRSA isolation rate was $8.6 \%$, and $2.9 \%$, while the nasal carriage rate was $5 \%$ and $1.6 \%$ in the first and second periods respectively. Mupirocin nasal application has resulted in nasal carriage clearance of six and two colonised HCWs in the first and second periods respectively.

The nosocomial infection rates and prevalence of MRSA infection in patients, along with nasal colonisation among HCWs, had lowered considerably. Infection control methods to contain MRSA outbreaks focus on surveillance to identify and isolate carriers. Adequate hand hygiene, isolation of infected patients and the use of barrier techniques such as gowns and gloves and education of staff on hygienic measures were crucial in controlling MRSA spread in the institute's hospital.

\section{Environmental measures}

Following discussions with the hospital manager, the team decided to introduce environmentally-friendly products for pest control. There has been a huge reduction in costs by introducing these products for pest control, costing the hospital fE4000 (approximately £380). The environmentally-friendly products are also found to be more effective than the chemical ones. More importantly, reports from different hospital departments concluded that the hospital is now completely free from any pests.

The hospital now uses the products for washing textiles, having benefits for both patients and the environment. In order to prevent air pollution, the use of a nonenvironmentally friendly incinerator is forbidden in the hospital.

\section{Establishing a central sterilisation unit}

The team convinced the institute's president and the hospital manager to retain this unit. The team members first went through the process of systematically removing everything from the room and finding alternative places. The team also got in touch with specialists in designing central sterilisation units in Egypt, who provided them with a design in line with international standards. Details of the design were then discussed with the engineering department and hospital manager.

One infection control nurse and two newly employed nurses have been trained and made responsible for the central sterilisation unit. Now the renewal of the central sterilization unit is going on and should be working as soon as possible.

\section{Aluminum-framed posters}

The team designed aluminium frames $(100 \mathrm{~cm}$ X 120 $\mathrm{cm}$ ) with glass covers capable of displaying eight posters with figures and guidelines. Suitable posters were designed to the local needs and requirements of each department, for example, cleaning and disinfection guidelines for endoscopes in the endoscope units or safer practices in laboratories.

These aluminium frames with the displayed posters were very effective in keeping the posters in proper condition, whilst making them easily available to be read and seen by healthcare workers.

\section{Raising awareness}

To raise the awareness and transmit the message that infection control is an international concern, not just a local interest, members of the infection control unit exert a great effort to successfully organise the following infection control conferences at the Theodor Bilharz Research Institute:

1. International Conference and Training Course on Recent Technology in the Field of Infection Control and Environmental Aspects in Hospitals,26-30 June 2004.

2. 2nd Infection Control Arab Conference. Antimicrobial Resistance: A Call to Combat?, Under The National Campaign of ESIC for Appropriate Use of Antimicrobials, 23-25 May 2005 (http:// www.emphis.org/events/ni/Event.E.8/).

3. 3rd International Infection Control Conference of Theodor Bilharz Research Institute. Updates on infection control to combat emerging infections, 18-20 December 2006. 
The participation of different health care workers, either engaged in infection control team or not, helped greatly to make them understand the importance of the issue and its implication on health and protection of both the patients and health care workers. Furthermore, mutual exchange of experiences highlighted their personal skills, acquired through the TBRI infection control unit, with further appreciation and respect to the unit's efforts.

\section{Conclusions}

The above is a summary of some of the major problems that the team faced through its work in the infection control unit at TBRI. In spite of limited financial resources, the team put in a lot of effort to implement these changes and provide these outcomes. 